\title{
Inhibition of 90Cu10Ni Alloy with 1-phenyl 1-H-tetrazole 5-thiol in Chloride Solution in Absence and Presence of Sulfide
}

\author{
Mohammad H. BinSabt ${ }^{*}$, Faizah M. Al-Kharafi, Ahmed Abdel Nazeer, Ahmed Galal \\ Department of Chemistry, Faculty of Science, Kuwait University, P.O. Box 5969 Safat 13060, Kuwait \\ *E-mail: binsabtm@gmail.com
}

doi: $10.20964 / 2017.02 .10$

Received: 22 October 2016 / Accepted: 29 November 2016 / Published: 30 December 2016

\begin{abstract}
The inhibiting effect of 1-phenyl 1-H-tetrazole 5-thiol (PhTT) on corrosion of copper-nickel alloy, $90 \mathrm{Cu}-10 \mathrm{Ni}$, in different electrolytes was studied. Polarization measurements were performed in sodium chloride solution in absence and presence of sulfide ions. The surface morphology and its structure were examined using SEM and EDX to evaluate the effect of using inhibitor. In absence of sulfide the inhibition in the studied media was attributed to the formation of protective film of $\mathrm{Cu}^{+}-$ tetrazole on the alloy surface. The rate of inhibition decreases with increasing temperature and the activation energy for the corresponding processes were determined. The presence of sulfide decreases the inhibition due to the incorporation of sulfur in the protective film that enhances the corrosion. SEM images revealed the formation of protective layers on the alloy surface in presence of PhTT which is affected in presence of sulfide with the inhibitor. In absence of sulfide EDX showed the presence of carbon, sulfur and nitrogen on alloy surface that proved the presence of the inhibitor on the alloy surface which decreases in presence of sulfide. The composition of the protective layer in polluted and non-polluted media studied with EDX was compared to the results obtained from the inductively coupled plasma analyses of the ions in the electrolyte side.
\end{abstract}

Keywords: 90Cu-10Ni alloy; Corrosion Inhibition; Sulfide; PhTT; SEM; EDX; ICP.

\section{FULL TEXT}

(C) 2017 The Authors. Published by ESG (www.electrochemsci.org). This article is an open access article distributed under the terms and conditions of the Creative Commons Attribution license (http://creativecommons.org/licenses/by/4.0/). 